\title{
IgG Subclass Deficiency in Children with IgA Deficiency Presenting with Recurrent or Severe Respiratory Infections
}

\author{
LORRAINE J. BEARD, ANTONIO FERRANTE, VIVI-ANNE OXELIUS, AND \\ GEORGE M. MAXWELL \\ Department of Paediatrics [L.J.B., A.F., G.M.M.], University of Adelaide. Adelaide Children's Hospital, South \\ Australia and Department of Paediatrics [V.-A.O.], University Hospital, Lund. Sweden
}

\begin{abstract}
A group of 22 children presenting with recurrent or severe respiratory tract infections who had low IgA levels (more than 2 SD below the mean for age) were examined for IgG subclass deficiency. Patients were screened for possible defects in neutrophil chemotaxis, bactericidal, fungicidal, and quantitative iodination activity, as well as for complement function. The majority of the patients showed IgG subclass levels below the mean for age. Nine of the children showed definite IgG subclass deficiency and at least two showed definite deficiency of more than one IgG subclass. The predominant subclass deficiency was found to be IgG1. While nine children showed IgG4 levels below the level detectable by the tecnhique used, it is not possible to assess whether these patients are deficient in this isotype since some healthy subjects also give values below the level of detection. Most of the patients who had very low (1-6 mg/dl) or undetectable $(<1 \mathrm{mg} / \mathrm{dl})$ levels of serum IgA did not show IgG subclass deficiencies, while IgG subclass deficiencies were common among those with borderline low IgA levels (slightly more than 2 SD below the mean for age). Nine children showed total IgG levels close to 2 SD below mean for age, and at least six of these showed IgG subclass deficiency. The result suggests that patients with recurrent and/or severe respiratory infections who have borderline IgA and IgG levels may have IgG subclass deficiencies and if they do could benefit from immunoglobulin therapy. (Pediatr Res 20:937-942, 1986)
\end{abstract}

\section{Abbreviation}

HBSS, Hanks' balanced salt solution

Selective IgA deficiency is relatively common. While some IgA-deficient subjects appear to be " normal," others are subject to various problems, e.g. recurrent infections, gastrointestinal tract diseases, autoimmune disorders, or malignancies (1). It has been suggested that IgG subclass deficiency may be an important factor in those patients with apparently isolated IgA deficiency who are subject to recurrent infections (2). However, this correlation still remains to be clearly defined, particularly in view of the fact that many such patients investigated previously were not assessed for deficiencies of complement or neutrophils. The

Received November 12, 1985; accepted May 14, 1986.

Correspondence Dr. A. Ferrante, University Department of Paediatrics, Adelaide Children's Hospital, S.A. Australia, 5006.

Supported in part by a University Research Grant of the University of Adelaide. purpose of the present study was to examine for possible IgG subclass deficiencies in patients with apparently selective IgA deficiency presenting with recurrent and/or severe respiratory infections and, in addition, to try to rule out possible complement and neutrophil abnormalities.

\section{MATERIALS AND METHODS}

Patients. Twenty-two children previously found to have apparently selective IgA deficiency, and presenting with recurrent and/or severe respiratory infections were studied. Their ages ranged from 0.4 to $13.8 \mathrm{yr}$, with a mean of $3.5 \mathrm{yr}$. Twelve were males and 10 females. Seven children had unusually frequent upper respiratory tract infections, e.g. sinusitis, tonsillitis, pharyngitis, otitis media and ill-defined "URTIs," eight had recurrent lower respiratory tract infections, as well as, in many cases, upper respiratory infections, and seven children had, in addition to multiple respiratory tract infections, serious or unusual infections in other sites. None of the children had cystic fibrosis, gastroesophageal reflux or other adequate explanations for their repeated and often severe infections.

Preparation of neutrophils. Neutrophils were prepared from heparinized-peripheral blood by the rapid single-step technique $(3,4)$. Briefly $5 \mathrm{ml}$ of blood from healthy volunteers were carefully layered onto $3 \mathrm{ml}$ of hypaque-ficoll medium of density 1.114 in $15 \times 115 \mathrm{~mm}$ conical polystyrene tubes. After centrifugation at $200-400 \times g$ for $30 \mathrm{~min}$ at room temperature, the second leukocyte-containing band, $1 \mathrm{~cm}$ below the first leukocyte band was harvested and shown to contain neutrophils of $>96 \%$ purity and $>99 \%$ viability (trypan blue dye exclusion technique). These were washed and resuspended in the appropriate tissue culture medium indicated below.

Chemotaxis. Neutrophil chemotaxis was assayed by the agarose technique (5) with some modification (6) using $\mathrm{N}$-formyl-Lmethionyl-L-leucyl-L-phenylalanine as the chemoattractant (7).

Bactericidal and fungicidal assays. To assay for neutrophil bactericidal and fungicidal activity the methods as described previously were used $(8,9)$. In the bactericidal assay $1 \times 10^{6}$ Staphylococcus aureus were added to $1 \times 10^{6}$ neutrophils in the presence of $5 \%$ human serum and in a total volume of $0.5 \mathrm{ml}$ in HBSS in screw-capped plastic tubes. The cells were gassed with $5 \% \mathrm{CO}_{2}$-air mixture and incubated at $37^{\circ} \mathrm{C}$ with end to end mixing. Samples were taken at 0,1 , and $2 \mathrm{~h}$ and plated on to nutrient agar to determine the number of viable bacteria.

Neutrophils were examined for ability to kill Torulopsis glabrata with cell numbers and conditions as described above for the bactericidal assay. The only differences were in the sampling time $(0,1.5,3 \mathrm{~h})$ and the plating onto nutrient media (Sabouraud agar).

Leukocyte iodination. The neutrophil iodination reaction used 
was similar to that described by Pincus and Klebanoff (10) modified to a semiautomated microassay (11). Neutrophils were resuspended in HBSS and $0.1 \mathrm{ml}$ of this suspension was added to each of the wells in the microtiter plates $\left(1 \times 10^{6}\right.$ cells $), 0.1$ $\mathrm{ml}$ of zymosan $(2.5 \mathrm{mg} / \mathrm{ml})$ and $0.05 \mathrm{ml}$ of $25 \%$ human serum diluted in HBSS containing sodium iodine $\left({ }^{125} \mathrm{I}\right)$. Controls received all the above except the zymosan.

Complement. Complement components $\mathrm{C} 3$ and $\mathrm{C} 4$ were quantitated with commercially available plates by the technique of radial immunodiffusion (Behringwerke, Marburg, W. Germany). The $\mathrm{CH}_{50}$ units were measured essentially as described previously (12). Briefly, sensitized sheep red blood cells were incubated with various dilutions of serum at $37^{\circ} \mathrm{C}$ for $30 \mathrm{~min}$. Lysis was estimated by measuring spectrophotometrically the hemoglobin released.

Measurement of immunoglobulin isotypes. Serum IgA, IgG, and IgM were measured by radial immunodiffusion technique using commercially available plates (Behringwerke). Age-related means \pm SD of these immunoglobulins in normals have been presented previously (13). IgG subclasses, IgG1, IgG2, IgG3, and IgG4 were measured by electroimmunoassay using polyclonal rabbit antiserum as described previously (14). Values for age related normal children have been described previously $(15,16)$. IgE was measured by the PRIST assay (Pharmacia, Sydney, Australia).

Statistics. Significance was analyzed by the Fisher exact probability test.

\section{RESULTS}

A summary of our findings is presented in Table 1. At least nine of the 22 children were found to have IgG subclass deficiency (deficiency being defined as below the lower limit of the age-related normal range). Of these nine, only one had a very low serum IgA level. The others had much less severe degrees of reduced $\operatorname{IgA}$ levels (Fig. 1). Six children had undetectable levels of serum IgA $(<1 \mathrm{mg} / \mathrm{dl})$ and none of these had a detectable IgG subclass deficiency. One other child had a very low serum IgA level $(6 \mathrm{mg} / \mathrm{dl})$ and no IgG subclass deficiency (Fig. 1). If a serum IgG4 level of $(<1 \mathrm{mg} / \mathrm{dl})$ were considered as a deficiency, it was found that in the group with markedly low $\operatorname{IgA}(\leq 6 \mathrm{mg} / \mathrm{dl})$, three showed IgG subclass deficiency while five were normal, and in the group with slightly low IgA (slightly more than 2 SD below the mean) 12 showed IgG subclass deficiency while two were normal. These results suggest that IgG subclass deficiency is more likely to be associated with slightly rather than with markedly low IgA levels $(p=0.05)$. Most children with IgG subclass deficiencies had total serum IgG levels close to $2 \mathrm{SD}$ below the mean (Fig. 1). None of the children studied had serum IgG levels more than the $2 \mathrm{SD}$ above the mean. Serum IgM levels did not appear to bear any relationship to the finding of $\mathrm{IgG}$ subclass deficiencies (Fig. 1). Serum IgE levels did not appear to be related to any of the IgG subclass levels (data not presented).

The most common IgG subclass deficiency found in our patients was that of IgG1, occurring in six patients, although in five of the six the level was only marginally below the normal range. In three of them it occurred as an isolated deficiency (P9, P12, and P15; Table 1; Fig. 2). In another patient it was associated with an IgG2 deficiency (P18; Table 1; Fig. 2) and in two with IgG4 levels of $<1 \mathrm{mg} / \mathrm{dl}$ (P4 and P11; Table 1; Fig. 2). Four of the six had total serum IgG levels close to 2 SD below the mean for age (Fig. 1).

Serum IgG2 subclass deficiency was found in four children. In three it was associated with a deficiency of either IgG1 or IgG3, or with undetectable IgG4 (P18, P20, and P3; Table 1; Fig. 2). Three of these children also showed total IgG levels nearly 2 SD below the mean for age.

Nine of our 22 patients had unmeasurable levels of serum IgG4 and these included all seven children who were $3 \mathrm{yr}$ old or less. Four of them had low normal IgE levels (Table 1).

A plot of IgG subclass levels against normal levels showed that
Table 1. A summary of clinical and immunological presentations*

\begin{tabular}{|c|c|c|}
\hline $\begin{array}{l}\text { Patient } \\
\text { (P) }\end{array}$ & Clinical problems & Immunological abnormalities \\
\hline 1 & $\begin{array}{l}\text { URTIS, salmonella } \\
\text { infection, UTI }\end{array}$ & $\begin{array}{l}\downarrow \mathrm{IgG} 4, \downarrow \text { neutrophil } \\
\text { bactericidal activity }\end{array}$ \\
\hline 2 & LRTIS & $\downarrow \downarrow \mathrm{IgA}, \downarrow$ IgG4 \\
\hline 3 & $\begin{array}{l}\text { LRTIS (shunted } \\
\text { hydrocephalus) }\end{array}$ & $\downarrow \downarrow \operatorname{Ig} A, \downarrow \operatorname{IgG} 2, \downarrow I g G 4$ \\
\hline 4 & LRTIS & $\downarrow \operatorname{IgG} 1, \downarrow$ IgG4 \\
\hline 5 & $\begin{array}{l}\text { LRTI, salmonella } \\
\text { and monilia in- } \\
\text { fections }\end{array}$ & $\downarrow \operatorname{IgG} 4, \downarrow$ chemotaxis \\
\hline 6 & $\begin{array}{l}\text { LRTIS, URTIS, } \\
\text { asthma }\end{array}$ & $\downarrow$ IgG4,$\downarrow \mathrm{C}_{4}$ \\
\hline 7 & URTIS, PUO & $\downarrow \downarrow \mathrm{IgA}, \downarrow \mathrm{IgG} 4$ \\
\hline 8 & LRTIS, URTIS & $\uparrow \operatorname{Ig} E$ \\
\hline 9 & URTIS & $\downarrow \operatorname{IgG1}$ \\
\hline 10 & URTIS & $\begin{array}{l}\downarrow \mathrm{C}_{4}, \mathrm{IgG} 2 \text { level close to } \\
\text { lower limit }\end{array}$ \\
\hline 11 & $\begin{array}{l}\text { URTIS, LRTIS, } \\
\text { pneumococcal } \\
\text { meningitis }\end{array}$ & $\downarrow \operatorname{IgG} 1, \downarrow \operatorname{IgG} 4, \uparrow \operatorname{IgE}$ \\
\hline 12 & LRTIS, URTIS & $\downarrow$ IgG1, $\downarrow$ chemotaxis \\
\hline 13 & $\begin{array}{l}\text { URTIS, herpes } \\
\text { simplex }\end{array}$ & $\downarrow \downarrow \operatorname{IgA}$ \\
\hline 14 & LRTIS, URTIS & $\downarrow$ IgG4 \\
\hline 15 & URTIS, asthma & $\downarrow$ IgG1 \\
\hline 16 & URTIS & $\downarrow \downarrow$ IgA \\
\hline 17 & $\begin{array}{l}\text { LRTIS, URTIS, } \\
\text { haemophilus } \\
\text { meningitis }\end{array}$ & $\downarrow$ IgG2, $\downarrow$ chemotaxis \\
\hline 18 & $\begin{array}{l}\text { LRTIS, URTIS, } \\
\text { hay fever }\end{array}$ & $\begin{array}{l}\downarrow I g G 1, \downarrow \operatorname{IgG} 2, \uparrow \operatorname{IgE}, \\
\downarrow \downarrow \text { bactericidal activity } \\
\downarrow \mathrm{C}_{4}\end{array}$ \\
\hline 19 & $\begin{array}{l}\text { LRTIS (bronchiec- } \\
\text { tasis), URTIS }\end{array}$ & $\downarrow \downarrow I g A, \uparrow \operatorname{IgE}$ \\
\hline 20 & $\begin{array}{l}\text { URTIS, "infectious } \\
\text { mononucleosis," } \\
\text { UTI }\end{array}$ & $\downarrow \mathrm{IgG} 2, \downarrow$ IgG3 \\
\hline 21 & LRTIS, URTIS & $\Downarrow \downarrow \operatorname{Ig} A$ \\
\hline 22 & $\begin{array}{l}\text { URTIS, asthma, } \\
\text { herpes zoster }\end{array}$ & $\downarrow \downarrow$ IgA, $\uparrow \operatorname{IgE}$ \\
\hline
\end{tabular}

* URTIS, upper respiratory tract infections, e.g. otitis media, tonsillitis, sinusitis; UTI, urinary tract infection; LRTIS = lower respiratory tract infections; $\downarrow$, decreased (see data in Figs.); $\uparrow$, increased; $\downarrow$ IgG4 indicates an IgG4 level of $<1 \mathrm{mg} / \mathrm{dl} ; \downarrow \downarrow$ IgA indicates $\leqslant 6 \mathrm{mg} / \mathrm{dl}$.

$16,17,15$, and 17 of the 22 patients had $\operatorname{IgG} 1, \operatorname{IgG} 2, \operatorname{IgG} 3$, or IgG4 levels below the mean values for age respectively (Fig. 2).

No patients demonstrated defects of either neutrophil iodination or fungicidal capacity (Fig. 3). Three children showed reduced neutrophil chemotaxis (P5, P12, and P17) and at least two of these were also IgG subclass deficient (P12 and P17; Table 1; Fig. 3). Two patients had reduced neutophil bactericidal capacity (P1 and P18) and at least one of these (P18) had IgG subclass deficiency (Table 1; Fig. 3). Serum $\mathrm{C} 3$ and $\mathrm{CH}_{50}$ were within normal limits in all patients. Reduced levels of $\mathrm{C} 4$ occurred in three children (P6, P10, and P18) and one of these had an IgG subclass deficiency (Table 1; Fig. 4). None of the children with extremely low IgA levels had defects in neutrophil function or deficiencies of complement.

\section{DISCUSSION}

Results from this study show that a group of patients with "selective" IgA deficiency who had a history of recurrent or severe respiratory tract infections fell into two almost distinct groups with respect to their display of $\mathrm{IgG}$ subclass deficiencies, 

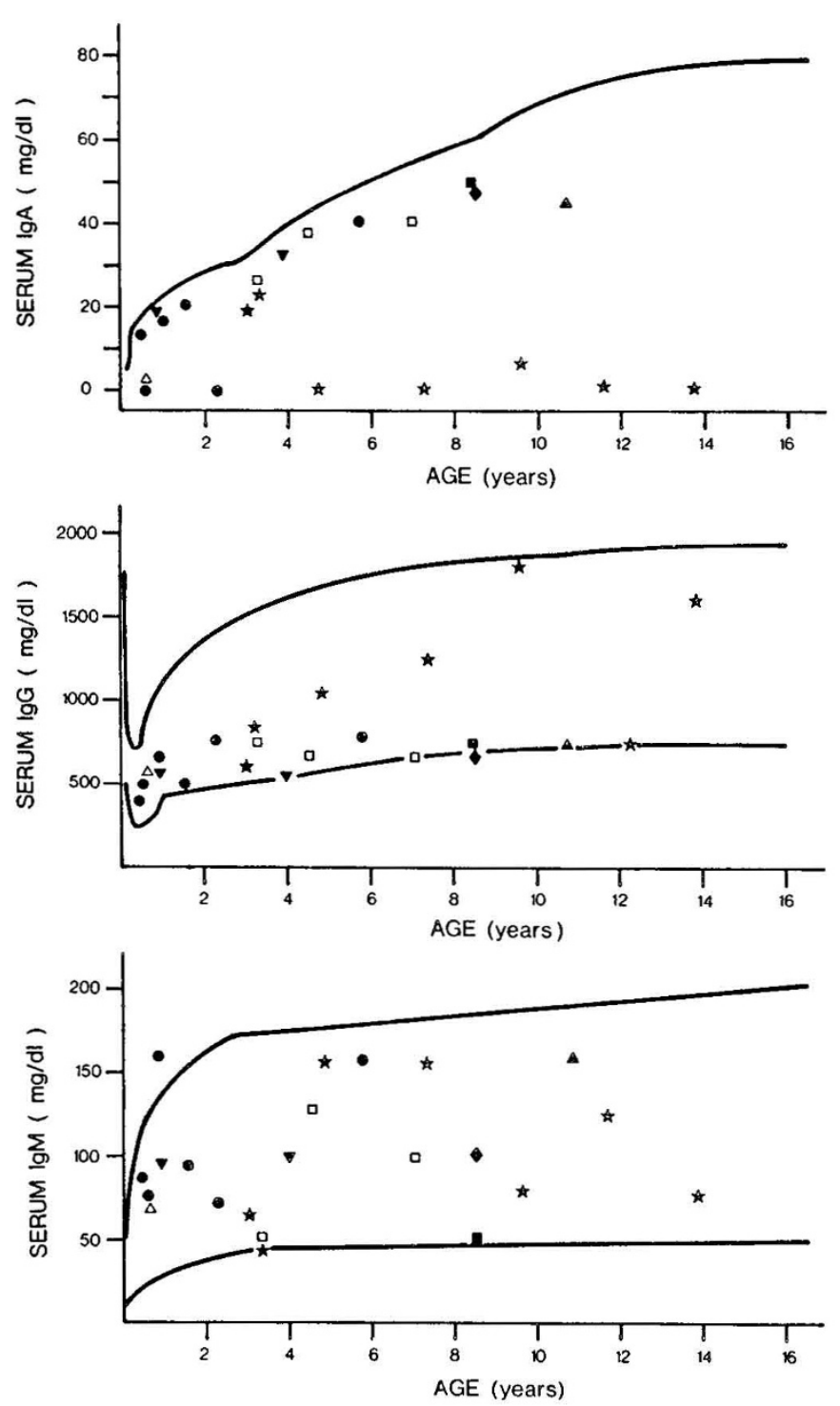

Fig. 1. Serum IgA, IgG, and IgM levels, and associated IgG subclass deficiencies in patients. The solid lines represent mean $\pm 2 \mathrm{SD}$ for $\mathrm{IgG}$ and IgM, and mean -2 SD for IgA for normals. No deficiency $(\star)$,

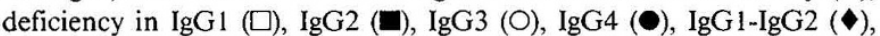
$\operatorname{IgG} 2-\operatorname{IgG} 3(\boldsymbol{\Delta}), \operatorname{IgG} 1-\operatorname{IgG} 4(\boldsymbol{\nabla}), \operatorname{IgG} 2-\operatorname{IgG} 4(\Delta)$. IgG4 deficiency refers to values $<1 \mathrm{mg} / \mathrm{dl}$.

i.e. those who had undetectable or very low $\operatorname{lgA}(\leqslant 6 \mathrm{mg} / \mathrm{dl})$ and who did not display subclass deficiencies, and those who had IgA levels close to 2 SD below the mean, many of whom did display IgG subclass deficiencies. Only one child who had a very low IgA level had a subclass deficiency. Seven of the eight children who had a very low, or undetectable level of $\operatorname{IgA}$ did not have an associated IgG1, IgG2, or IgG3 deficiency. None of them had either neutrophil defects (in chemotaxis, bactericidal activity, or quantitative leukocyte iodination) or complement deficiencies.

Oxelius et al. (2) studied 37 IgA deficient patients ( 22 children) and showed that 26 of the 30 with serum IgA levels $<5 \mathrm{mg} / \mathrm{dl}$ had no IgG subclass deficiencies. While three of our eight children with very low or undetectable IgA levels had serum IgG4 of $<1 \mathrm{mg} / \mathrm{dl}$, without a more sensitive assay for IgG4 measurement, we can only speculate that they may have had $\mathrm{IgG} 4$ deficiency.

Ugazio et al. (17) reported that in a group of 13 IgA deficient children with recurrent respiratory infections, subclass deficiencies were common, but in four of five children with very low IgA levels $(<0.5 \mathrm{mg} / \mathrm{dl})$ no subclass deficiency occurred. This study, considered in conjunction with ours, suggests that in children very low or undetectable IgA levels may predispose to recurrent respiratory infections in the absence of an associated IgG subclass deficiency. Burgio et al. (18), in a series of 50 children with IgA deficiency, showed that infections were a problem in $77 \%$ of those with absent IgA, but in only $20 \%$ of those with partial IgA deficiency. Our study rules out neutrophil defects and complement deficiency as contributory factors indicating that the very low IgA itself may be significant. The situation in adults may be different as there may be as many healthy adults with undetectable as with slightly low levels of IgA (19). Some investigators have found that low IgA in healthy adults is associated with increased IgG (19) which may compensate for the deficiency and possibly explain why these subjects are not infection prone. None of our children with very low IgA had raised IgG levels. The inability to compensate for a lack of $\operatorname{IgA}$ by increasing IgG may be a factor and may be age related.

In the other 14 of our patients who had IgA levels close to 2 SD below the mean, deficiencies of $\operatorname{IgG} 1$, IgG2, or IgG3 were common. In fact, they occurred in eight of these 14 children. Ugazio et al. (17) found an even higher incidence of subclass deficiencies in 13 IgA-deficient children with respiratory infections, and reported IgG2 subclass deficiencies in all four children who had IgA levels above $5 \mathrm{mg} / \mathrm{dl}$ but more than $2 \mathrm{SD}$ below the age-normal mean. Oxelius et al. (2) have suggested that IgG subclass deficiency may be responsible for proneness to infections in some IgA-deficient subjects. Our results like those of Ugazio et al. (17) would support this suggestion in children with mildly reduced IgA levels. Our results appear different from those of several other studies in that our predominant subclass deficiencies appear to be those of IgG1 and possibly IgG4 whereas others have generally seen deficiencies of IgG2 (and possibly IgG4), sometimes with an elevated IgG1 $(2,10,16,17)$. However, five of our six IgG1-deficient children had levels only marginally below the age related normal range.

Six patients of our total group of 22 IgA-deficient children, and of the nine with a deficiency of either IgG1, IgG2, or IgG3, showed IgG1 deficiency; three had an isolated IgG1 deficiency, two had a possible combined IgG1-IgG4, one had combined IgG1-IgG2. Only one of the IgG1-deficient patients (isolated IgGl deficiency) had a neutrophil chemotactic defect and another had decreased bactericidal activity and decreased $\mathrm{C} 4$.

Thus it is unlikely that either a neutrophil defect or complement deficiency could explain the infection proneness in the majority of these children.

There have been some other reports of patients with IgG1 deficiency and problems with coping with infections. Schur et al. (21) described two children and an adult patient with lifelong susceptibility to pyogenic respiratory infections in whom low serum IgG1 levels were found concurrently with other subclass deficiencies; namely IgG1-IgG2-IgG4, IgG1-IgG2, and IgG1-IgG2-IgG3. Consistent with our finding, these patients' sera demonstrated a diminished IgG level on immunoelectrophoresis. However, unlike our results, the IgA was normal or increased.

Only four of our 22 children showed IgG2 deficiency. One had an isolated IgG2 deficiency and the other three had combined IgG1-IgG2, IgG2-IgG3, and IgG2-possible IgG4 deficiency, respectively. One had a chemotactic defect and another decreased bactericidial activity and slightly low $\mathrm{C} 4$. Although this incidence of IgG2 deficiency appears much less than the finding of Ugazio et al. (17) of $\operatorname{IgG} 2$ deficiency in as many as eight of $13 \operatorname{lgA}$ deficient children with recurrent respiratory infections, it is evident that 16 of our 22 patients had IgG2 levels below the mean for age. Oxelius et al. (2) found IgG2 deficiency in seven patients with respiratory infections in a group of $37 \mathrm{IgA}$-deficient patients with various illnesses. While this overall incidence of IgG2 deficiency is similar to ours, the incidence in the subgroup of these 37 who had respiratory infections would be higher. Conversely Cunningham-Rundles et al. (20) found IgG2 deficiency in only 

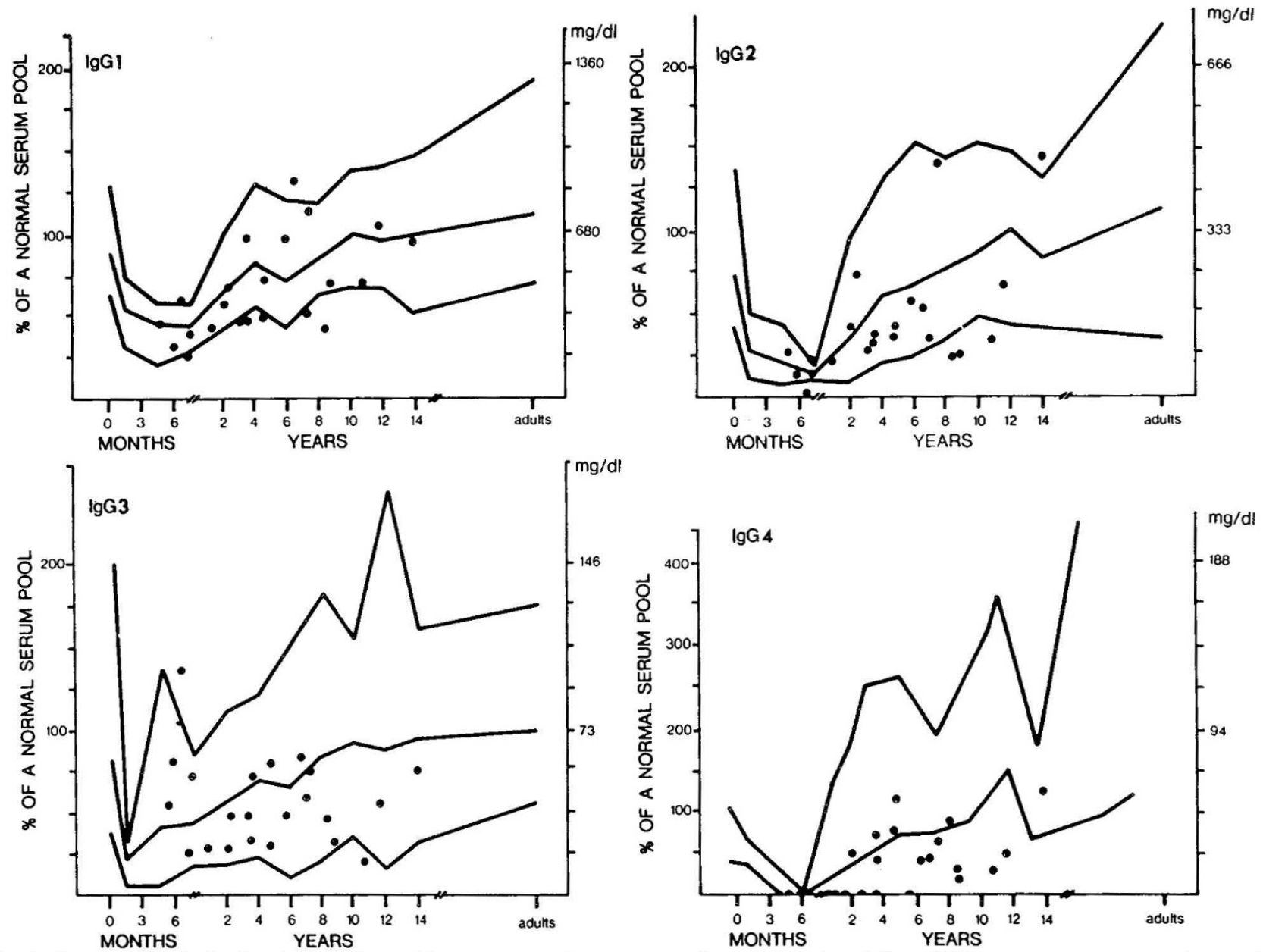

Fig. 2. Serum IgG subclass levels in patients with recurrent and or severe respiratory infections. The solid lines represent mean and normal range for age for IgG1, IgG2, and IgG3, and mean plus upper limit of range for IgG4. Circles represent serum levels in patients and semicircles represent levels that were $<1 \mathrm{mg} / \mathrm{dl}$.

four of 39 patients with IgA deficiency but these were patients at a cancer center and may therefore represent an unusually selected group. Four of our six IgG1-deficient patients and three of our four IgG2-deficient patients had total IgG close to 2 SD below the mean. This is not surprising as IgG1 and IgG2 normally make about 66 and $23 \%$ of total serum IgG, respectively.

Nine of the 22 children in our study showed IgG4 levels of $<1$ $\mathrm{mg} / \mathrm{dl}$. It can only be speculated that some of these may be $\mathrm{IgG} 4$ deficient since some normal healthy individuals are also found to have IgG4 levels below the detection level of the assay system used in this study. However, our finding of a $38 \%$ incidence of IgG4 of $<1 \mathrm{mg} / \mathrm{dl}$ is higher than that expected in the normal population. Heiner (22), using a sensitive radioimmunoassay, came to the conclusion that the absence of serum IgG4 is usually associated with severe recurrent sinopulmonary infections.

Since antipolysaccharide antibodies are generally of the IgG2 type $(23,24)$, susceptibility to pyogenic infections would be expected to be associated with IgG2 deficiency. In addition, studies have suggested that antibodies to the polyribose phosphate antigen of Haemophilus influenzae and to Streptococcus pneumoniae polysaccharide can be of the IgG4 as well as the IgG2 isotype (22). Oxelius (25) reported an inability of subjects with $\mathrm{IgG} 2-\mathrm{IgG} 4$ deficiency to produce antibodies to bacterial polysaccharide antigens and also found that otitis-prone children, particularly when the pathogen was haemophilus, had reduced IgG2 but not IgG1, IgG3, or IgG4 (16). There were 12 children in our series in whom recurrent otitis media was a problem, and in only one of these (P18) was IgG2 deficient. Four of them had low IgG1 levels, four had IgG4 levels of $<1 \mathrm{mg} / \mathrm{dl}$, and 4 had extremely low IgA. While the pathogens were not identified in three of our IgG2-deficient children, it is of interest that one child in our series who had a documented haemophilus infection (meningitis) was IgG2 deficient (P17). It seems that in children antibodies to carbohydrate antigens such as pneumococcal polysaccharide, teichoic acid, and dextran are predominantly of the IgG1 isotype (26). The pathogens involved in the infections occurring in our IgG1-deficient children were not generally identified, but one of these children had had pneumococcal disease (meningitis) (P11).

Oxelius et al. (2) reported six patients with recurrent upper respiratory tract infections and one with chronic pulmonary infection, bronchiectasis, and malabsorption who had both $\operatorname{IgA}$ and $\mathrm{IgG} 2$ deficiencies. The study also demonstrated that while the 11 healthy subjects with IgA deficiency were not IgG2 deficient, seven of 37 patients with illnesses and IgA deficiency, were IgG2 deficient. Three of our four patients who were deficient in IgG2 (and IgA) had had pneumonias (P3, P17, and P18) and the other had had upper respiratory tract infections (P20).

$\operatorname{IgG} 2$ and $\operatorname{IgG} 4$ subclass deficiencies may be associated $(2,16$, 25 ). Undetectable IgG4 levels occurred in six of seven of the IgG2-IgA-deficient subjects studied by Oxelius et al. (2). However, only one of our four IgA-IgG2-deficient patients had an undetectable IgG4 level (P3).

Our results suggest that a mild degree of IgA deficiency in children with recurrent infections may often be associated with IgG subclass deficiency, particularly when the total serum IgG is in the low-normal range. Additionally, our results suggest that an extremely low IgA level (as an isolated deficiency) may predispose children to recurrent infections. Infections in such children could not be explained by either a neutrophil defect or 

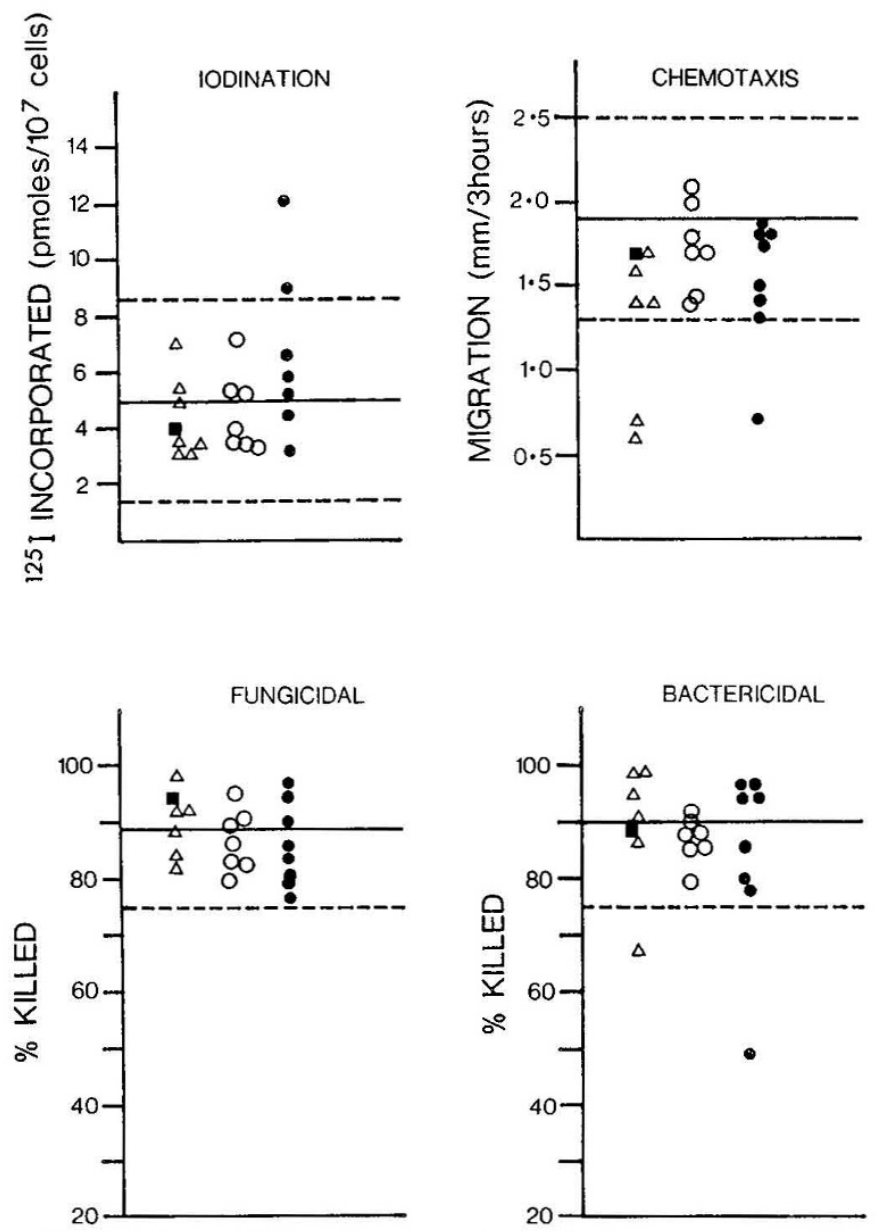

Fig. 3. Neutrophil functions in patients. Patients are grouped into those showing $\operatorname{IgG}$ subclass deficiency $(\Delta)$, very low IgA levels $(O)$, both of these two $(\square)$, or neither of the above $(\bullet)$. The solid line represents mean and the broken line \pm 2 SD of healthy children.

complement deficiency. However, our conclusions must be considered with care since we were unable to relate IgG subclass levels of patients to healthy controls of similar sex, ethnic, and geographic background.

The finding that IgG subclass deficiencies may play a role in increased proneness to infection has important therapeutic implications in the management of children with recurrent respiratory infections. Early detection of the hypogammaglobulinemia followed by adequate treatment (efficient immunoglobulin prophylaxis plus antibiotic support) may be the key to preventing the development of chronic and disabling pulmonary disease.

Acknowledgments. The authors are indebted to Barbara MacGregor and Jane Raphael for secretarial assistance.

\section{REFERENCES}

1. Hanson LA, Brandtzaeg P 1980 The mucosal defence system. In: Steihm RT, Fulginiti V (eds) Immunologic Disorders in Infants and Children, 2nd ed. WB Saunders, Philadelphia, pp 137-164

2. Oxelius V-A, Laurell AB, Lindquist B, Henryka G, Axelsson U, Bjorkander J, Hansen LA $1981 \mathrm{IgG}$ subclasses in selective IgA deficiency. Importance of IgG2-IgA deficiency. N Engl J Med 304:1476-1477

3. Ferrante A, Thong YH 1980 Optimal conditions for simultaneous purification of mononuclear and polymorphonuclear leucocytes from human blood by the Hypaque-Ficoll method. J Immunol Methods 36:109-117

4. Ferrante A, Thong YH 1982 Separation of mononuclear and polymorphonuclear leucocytes from human blood by the one-step hypaque-ficoll method is dependent on blood column height. J Immunol Methods 48:81-85

5. Nelson RD, Quie PG, Simons RL 1975 Chemotaxis under agarose: a new and simple method for measuring chemotaxis and spontaneous migration of human polymorphonuclear leukocytes and monocytes. J Immunol 115:1650-1656
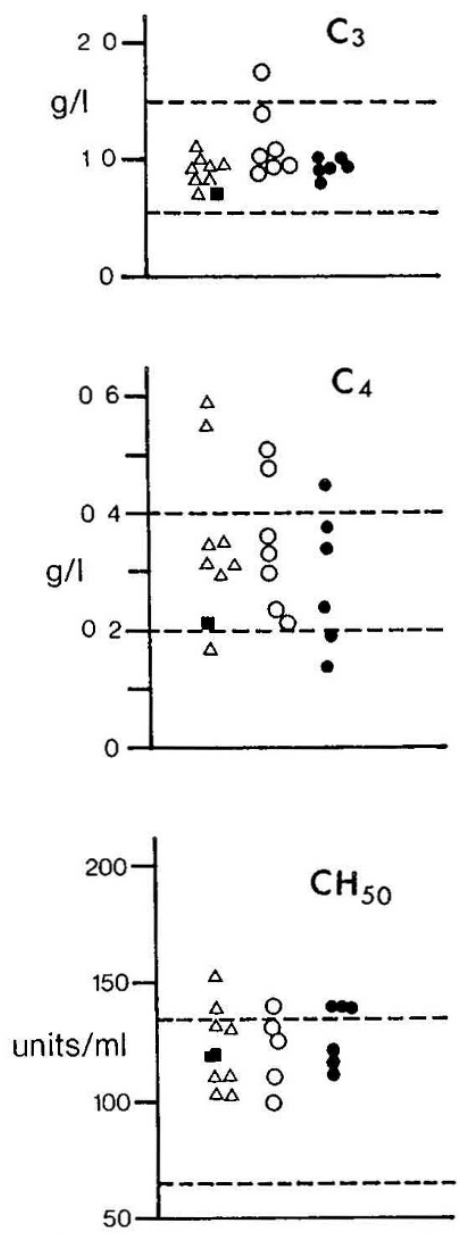

Fig. 4. Levels of the complement components $\mathrm{C} 3$ and $\mathrm{C} 4$, and hemolytic complement $\left(\mathrm{CH}_{50}\right)$ in patients' serum. Patients are grouped into those showing IgG subclass deficiency $(\triangle)$, very low IgA levels $(O)$, both of these ( $\square)$, or neither of the above $(\bullet)$. Lines depict normal range.

6. Ferrante A, Beard LJ, Thong YH 1980 Early decay of human neutrophil chemotactic responsiveness following isolation from peripheral blood. Clin Exp Immunol 39:532-537

7. Ferrante A 1985 Inhibition of human neutrophil locomotion by the polyamine oxidase-polyamine system. Immunology 54:785-790

8. Thong YH, Ferrante A, Ness D 1977 Neutrophil phagocytic and bactericidal dysfunction induced by bilirubin. Aust Paediatr J 13:287-289

9. Thong YH, Ness D, Ferrante A 1979 Effect of bilirubin on the fungicidal capacity of human neutrophils. Sabouraudia 17:125-129

10. Pincus SH, Klebanoff SJ 1971 Quantitative leukocyte iodination. N Engl J Med 284:744-750

11. Thong YH, Ferrante A 1978 A semi-automated microassay technique for quantitative leukocyte iodination. J Immunol Methods 20:297-299

12. Ferrante A, Rowan-Kelly B 1983 Activation of the alternative pathway of complement by Acanthamoeba culbertsoni. Clin Exp Immunol 54:477-485

13. Beard LJ, Maxwell GM, Thong YH 1981 Immunocompetence of children with frequent respiratory infections. Arch Dis Child 56:101-105

14. Oxelius V-A 1978 Crossed immunoelectrophoresis and electroimmunoassay of human IgG subclasses. Acta Pathol Microbiol Scand [Sect C]86:109-116

15. Oxelius V-A $1979 \mathrm{IgG}$ subclass levels in infancy and childhood. Acta Paediatr Scand 68:23-27

16. Oxelius V-A 1984 Immunoglobulin G ( $\mathrm{IgG}$ ) subclasses and human disease. Am J Med 76:7-18

17. Ugazio AG, Out TA, Plebani A, Duse M, Monafo V, Nespoli L, Burgio GR 1983 Recurrent infections in children with "selective" IgA deficiency: association with IgG2 and IgG4 deficiency. Birth Defects 19:161-171

18. Burgio GR, Druse M, Monafo V, Ascione A, Nespoli L 1980 Selective IgA deficiency: Clinical and immunological evaluation of 50 pediatric patients. Eur J Pediatr 133:101-106

19. Ropars C, Muller A, Paint N, Beige D, Avenard G 1982 Large scale detection of IgA deficient blood donors. J Immunol Methods 54:183-189

20. Cunningham-Rundles C, Oxelius V-A, Good RA 1983 IgG2 and IgG3 subclass deficiencies in selective IgA deficiency in the United States. Birth Defects 19:173-175

21. Schur PH, Borel H, Gelford EW, Alper CA, Rosen FS 1970 Selective gamma$\mathrm{G}$ globulin deficiencies in patients with recurrent pyogenic infections. N Engl J Med 283:631-634 
22. Heiner DC 1984 Significance of immunolgobulin G subclasses. Am J Med 76:1-6

23. Riesen WF, Skvaril F, Braun DB 1976 Natural infection of man with group A streptococci: levels; restriction in class, subclass and type; and clonal appearance of polysaccharide-group-specific antibodies. Scand J Immunol 5:383390

24. Yount WJ, Dorner MM, Kunkel HG, Kabat EA 1968 Studies on human antibodies $\mathrm{V} 1$ selective variations in subgroup composition and genetic markers. J Exp Med 177:633-646

25. Oxelius V-A 1974 Chronic infections in a family with hereditary deficiency of IgG2 and IgG4. Clin Exp Immunol 17:19-27

26. Hammarstrom L, Persson MAA, Smith CIE 1985 Immunoglobulin subclass distribution of human anti-carbohydrate antibodies: aberrant pattern in IgAdeficient donors. Immunology 54:821-826

\title{
Announcements
}

\author{
Annual Meeting
}

The American Pediatric Society and The Society for Pediatric Research announce the abstract deadline for the 1987 Annual Meeting (April 27-May 1, Disneyland Hotel, Anaheim, CA) has been set as December 3, 1986.

For further information contact: SPR-Debbie L. Wogenrich, The Society for Pediatric Research, Department of Pediatrics, UNM School of Medicine, Albuquerque, NM 87131 (505)277-6629 or APS-Dr. Audrey K. Brown, Secretary-Treasurer, Department of Pediatrics, Box 49, SUNY, Health Sciences Center at Brooklyn, 450 Clarkson Avenue, Brooklyn, NY 11203, (718)270-1692.

\section{Pediatric Hematology-Oncology Examination}

The Sub-Board of Pediatric Hematology-Oncology of the American Board of Pediatrics will administer its next certifying examination on Friday, July 10, 1987.

The following criteria must be met to be eligible to sit for the examination: 1. Certification by the American Board of Pediatrics. 2. Physicians who entered pediatric hematology-oncology training prior to January 1, 1986, may apply for admission to the examination on the basis of their completion of two years of subspecialty residency training in pediatric hematology-oncology. 3. Verification of training and recommendation by Program Director.

Each application will be considered individually and must be acceptable to the Sub-Board of Pediatric Hematology-Oncology.

Registration for this examination will extend from October 1, 1986, to January 31, 1987. Requests for applications received prior to the opening of registration will be held on file until that date, at which time application materials will be sent to those who have requested them.

The application fee for the examination is $\$ 800$ (\$275 processing and evaluating fee plus $\$ 525$ examination fee). Candidates not approved to take the examination will be refunded the $\$ 525$ examination fee. The processing and evaluating fee will be retained.

Please direct inquiries to the American Board of Pediatrics, 111 Silver Cedar Court, Chapel Hill, NC 27514-1651. Telephone (919) 929-0461. 